\title{
O PRINCÍPIO DA DIFERENÇA PARA ALÉM DA MERA COMPENSAÇÃo
}

\section{THE PRINCIPLE OF DIFFERENCE BEYOND MERE COMPENSATION}

\author{
${ }^{1}$ José Claudio Monteiro de Brito Filho \\ ${ }^{2}$ Homero Lamarão Neto
}

\section{RESUMO}

O artigo objetiva analisar a disposição do princípio da diferença na teoria de John Rawls, visando demonstrar a possibilidade de interpretar seu sentido mais amplo como garantia de padrão mínimo adequado às necessidades individuais. Ainda que o liberalismo de princípios não conceba expressamente a criação de um standard de bem estar social, a interpretação do princípio da diferença pode proporcionar a ideia de que indivíduos racionais, em equilíbrio reflexivo, não celebrariam acordos desprovidos da conotação mínima de justiça distributiva, sobejamente quando se está em jogo o acesso a bens escassos em uma sociedade idealizada como sistema de cooperação.

Palavras Chave: Equilíbrio Reflexivo - Justiça - Liberalismo - Princípios - Racionalidade.

\begin{abstract}
The article aims to analyze the layout of the difference principle in the theory of John Rawls, aiming to demonstrate the ability to interpret its broadest sense as a minimum standard of security appropriate to individual needs. Although liberalism principles not expressly conceives the creation of a standard of social welfare, the interpretation of the principle of difference can provide the idea that rational individuals in reflective equilibrium, there would celebrate agreements devoid of the minimum connotation of distributive justice, widely when you are in play access to scarce goods in a society conceived as a system of cooperation.
\end{abstract}

Keywords: Reflective Equilibrium - Justice - Liberalism - Principles - Rationality.

\footnotetext{
${ }^{1}$ Doutor em Direito pela Pontifícia Universidade Católica - PUC, São Paulo, (Brasil). Professor do Programa de Pós-Graduação e do Curso de Graduação em Direito do Centro Universitário do Pará - CESUPA, Belém, Pará, (Brasil). E-mail: jclaudiobritofilho@gmail.com

${ }^{2}$ Doutorando em Direito pela Universidade Federal do Pará - UFPA, Belém, (Brasil). Juiz Membro da Comissão de Direitos Humanos do Tribunal de Justiça do Estado do Pará. E-mail: homerolamaraoneto@ yahoo.com.br
} 


\section{INTRODUÇÃO}

As contribuições de John Rawls à conotação moderna de justiça distributiva e à filosofia política, em linhas gerais, são inquestionáveis. O padrão ralwsiano rompeu paradigmas, estabelecendo novos contornos para análise de critérios de justiça, da correção de desigualdades e da divisão de bens considerados escassos na sociedade.

A leitura de sua teoria, em qualquer caso, ainda é alvo de aprofundados debates, dispostos em interpretações bastante opostas acerca de seus elementos intrínsecos. Não por outra razão, as manifestações sobre o funcionamento dos princípios de justiça, especialmente o princípio da diferença, geram posições acadêmicas corriqueiramente antagônicas.

Neste ensaio sustentamos que o princípio da diferença deve ser interpretado não como elemento propiciador de mera compensação às desvantagens, porém como mecanismo central para construção de um pensamento sólido em torno de que aos indivíduos é garantido um mínimo adaptado de acordo às suas necessidades especiais, quando houver risco demonstrado de ausência de concretude no exercício de suas liberdades básicas, sem que essas peculiaridades sejam atendidas. Esse pensamento é respaldado pelos próprios elementos inseridos por Rawls, em sua teoria, sobejamente a racionalidade dos indivíduos representativos, os juízos ponderados em equilíbrio reflexivo, a solidariedade que respalda a sociedade de cooperação e o desconhecimento de condições peculiares que norteia a posição original.

Em razão do problema, e dos objetivos do estudo, a pesquisa desenvolvida é uma pesquisa teórica, e que estará focada especialmente na obra "Uma teoria da justiça" em que Rawls aborda a temática proposta, como ficará mais claro ao longo da exposição que será desenvolvida.

\section{PRIMEIRAS CONSIDERAÇÕES}

Deve o princípio da diferença, na teoria da justiça como equidade, de John Rawls, ser entendido como mera compensação, ou deve ter um papel mais concreto, mais proeminente?

O objetivo deste breve ensaio é responder afirmativamente à segunda hipótese, demonstrando a possibilidade de interpretar seu sentido mais amplo como garantia de um padrão mínimo adequado às necessidades individuais. 
Para isso, os principais aspectos da teoria de Rawls serão apreciados nos itens seguintes, firmando as bases necessárias para a compreensão da hipótese que será aqui defendida.

Além disso, serão necessárias algumas palavras a duas outras concepções de justiça, também em aspectos que interferem nas discussões que aqui serão travadas: o utilitarismo e o libertarismo. Começaremos com a concepção utilitarista.

\section{UTILITARISMO, DIREITOS E BEM ESTAR}

As concepções liberais efusivamente difundidas no século XVIII propiciaram duas revoluções que modificaram o padrão jurídico e institucional do mundo ocidental: a revolução norte-americana, em 1776, e a revolução francesa, em 1789. Com esses ideais, as formulações utilitárias também marcaram época, imprimindo um novo conceito sobre moralidade, agora despido de preceitos divinos ou abstratos.

Rachels (2006, p. 92-93) sustenta que o utilitarismo foi proposto por David Hume, porém Jeremy Bentham e John Stuart Mill é que teriam propiciado as formulações definitivas do que se consagrou como uma intensa modificação do pensamento do ser humano no século XIX.

Bentham defendia a existência de um único princípio moral fundamental, identificado como princípio da utilidade, balizador das condutas humanas. Por este princípio, a aprovação ou desaprovação de qualquer conduta dependeria da quantidade de felicidade que se pudesse causar à pessoa cujo interesse estivesse em jogo. Assim, a moral, e consequentemente, a justiça de uma conduta seriam constatadas se aumentasse a quantidade de felicidade.

Ainda conforme Rachels (2006, p. 104), a versão clássica da teoria, porém, teria obtido nova formatação com as formulações subsequentes de John Stuart Mill, com a obra "O Utilitarismo", de 1861, firmando-se três premissas para sua composição: a) a correção ou não de uma ação depende exclusivamente da virtude de suas consequências; b) a avaliação dessas consequências é feita exclusivamente pela quantidade de felicidade ou infelicidade proporcionada; c) a felicidade de cada pessoa tem um peso igual ou o mesmo valor para o cálculo utilitário.

Merece registro a ponderação de Sandel (2012, p. 64-66), no sentido de que a tentativa de Mill de reforçar a teoria utilitarista, na realidade, teria provocado um desvirtuamento da sua concepção básica quando, por exemplo, apela para valores morais além dos utilitários. 
Os novos preceitos defendidos por Mill, no princípio da utilidade, concentraram-se na análise de "valores mais elevados". Assim, enquanto a concepção inicial de Bentham dotava a aferição da moralidade do ato exclusivamente em decorrência de suas consequências, ou seja, do saldo líquido de felicidade apresentado, a nova versão defendia que uma conduta poderia, num determinado momento, apresentar elevado índice de satisfação, porém, a longo prazo, esse prazer poderia ser descaracterizado.

Um exemplo pitoresco para compreender essa nova feição desencadeada pode ser verificado no âmbito universitário. Alunos do curso de Direito que optam por não comparecer à classe de filosofia política para jogar futebol, e que acreditem severamente que o futebol pode lhes proporcionar maior prazer do que o estudo de teorias da justiça, certamente poderão encontrar maior saldo de felicidade momentânea na partida, mas, a longo prazo, com a deficiência de sua formação, poderão não creditar tanto valor àquela felicidade instantânea.

Dois pontos são enaltecidos nessa teoria plenamente classificada como consequencialista: a) enquanto padrão de moralidade, há uma preocupação com o bem estar das pessoas; b) é uma teoria que prega o igualitarismo e tal fator deve ser reconhecido como extremamente relevante para os padrões da época, pois garante a igualdade de condições para o exercício do cálculo (em busca da felicidade). Sobre as inovações do pensamento utilitarista, Kymlicka (2006, p. 60) sustenta:

Argumentei que o utilitarismo poderia justificar o sacrifício dos membros fracos e impopulares da comunidade para o benefício da maioria. Contudo, o utilitarismo também foi usado para atacar os que detêm privilégios injustos à custa da maioria. Na verdade, o utilitarismo, como movimento político e filosófico consciente de si, surgiu como uma crítica radical da sociedade inglesa. Os utilitários originais eram "Radicais Filosóficos" que acreditavam em repensar completamente a sociedade inglesa, uma sociedade cujas práticas eles acreditavam não ser produto da razão, mas da superstição feudal. O utilitarismo, nesse tempo, era identificado como um programa político progressista e preocupado com reformas - a ampliação da democracia, a reforma penal, as provisões para o bem estar social etc.

Dentro das limitações impostas a este artigo, não serão conferidos destaques às proposições subsequentes ao utilitarismo clássico, adotadas com o fito de refutar as críticas que lhe foram outorgadas, bastando, nesse momento, a simples menção da existência dessas reformulações direcionadas ao seu aperfeiçoamento.

Contudo, a despeito dessas tentativas de aperfeiçoamento, merece registro o fato de que o mesmo ponto de enaltecimento, o valor igual conferido às pessoas na determinação da maximização da felicidade, também gerou uma concentração demasiada das críticas 
endereçadas ao utilitarismo, justamente pela inviabilidade de se aferir a pertinência de cada vontade diante de tão díspares circunstâncias.

A versão clássica do utilitarismo, então, apesar de pregar um sistema aleatório de igualdade, diversamente do padrão de justiça como equidade proposto por John Rawls, que trataremos no próximo item, concentra-se na ideia de uma justiça a posteriori, medida de forma absolutamente circunstancial, sugerindo que a satisfação da maioria no grupo poderá sufocar a manifestação de pensamento e de credo religioso de uma minoria, por exemplo.

Da mesma forma, programas governamentais destinados a atender às necessidades básicas de saúde e educação estarão vinculados à cobertura da maioria, ou ao que sejam as necessidades da maioria, tornando-se irrelevante, do ponto de vista moral, a manutenção de parte do grupo social à margem da tutela de condições mínimas de vida, imprescindíveis à caraterização de uma vida digna.

As políticas públicas desencadeadas pelo Estado, na concretização dos direitos fundamentais, atingem sua moralidade - sendo então consideradas justas - quando proporcionarem a maior quantidade de satisfação aos indivíduos, desvinculando-se de qualquer análise prévia do justo.

Em suma, enquanto concepção essencialmente teleológica, o utilitarismo preconiza o bem antes do justo. O que importa é o saldo líquido do resultado, independentemente de como as pessoas serão tratadas pelo Estado. Assim, todas as políticas públicas norteadas por essa concepção podem ser consideradas justas a partir do momento em que a maioria tenha sido atendida, independentemente de se aferir, concretamente, que uma parcela do grupo social seja ignorada em suas pretensões.

Sob esse prisma, é primordial ressaltar que o utilitarismo, enquanto concepção de definição de preceitos morais, não se apresenta em condições de estabelecer um rol de direitos fundamentais, na medida em que os julgamentos morais são instáveis e maleáveis.

A partir dessas ponderações, pode-se afirmar que é inconcebível a explicação de um padrão de justiça concentrado fora de uma base moral preestabelecida. A permissão de analisar o justo somente pelos resultados alcançados outorga uma inevitável supressão de direitos fundamentais e a desvinculação da comunidade às obrigações morais.

Partindo justamente desse entendimento, John Rawls propôs uma nova concepção de justiça contrária à tônica utilitarista, na qual os preceitos morais outorgassem à sociedade mecanismos para estabelecimento de princípios orientadores da estrutura básica da sociedade, em que as liberdades fundamentais fossem prioritariamente asseguradas. 
Na próxima seção analisaremos os contornos básicos dessa teoria e, após tecermos considerações breves sobre o libertarismo de Robert Nozick, vincularemos sua interpretação à ótica da sequência dos quatro estágios definidos por Rawls, escalonados para a aplicação dos dois princípios de justiça escolhidos para reger as instituições públicas.

\section{JUSTIÇA COMO EQUIDADE}

Em 1971, John Rawls lançou "Uma teoria da justiça", marco filosófico na interpretação da virtude considerada a primeira das instituições sociais, objetivando edificar seu raciocínio na escolha de princípios regentes da justiça como equidade, a partir de um contratualismo hipotético. Sua compreensão exponencial respalda a reformulação ou abolição de leis e instituições injustas, ainda que se apresentem eficientes e bem organizadas.

Credita à justiça a qualidade de virtude primeira das instituições sociais, assim como a verdade seria dos sistemas de pensamento, razão pela qual a verdade e a justiça não aceitariam compromissos, repudiando por completo a ideia utilitarista de que o bem estar da maioria poderia justificar o cerceamento das liberdades da cidadania igual.

Enquanto teoria contratualista liberal, a justiça como equidade não tolera um arranjo institucional em que os indivíduos estejam despidos de segurança em suas liberdades, porque essa condição é precípua para que se alcancem seus planos racionais de vida. Quaisquer que sejam esses planos, os indivíduos necessitam de uma estrutura básica e um núcleo mínimo de direitos que sustente sua execução.

Parte Rawls da ideia de que as pessoas, de uma forma geral, possuem o senso de obediência civil, comportando-se de acordo com as normas de conduta que especificam um sistema de cooperação, criado para promover o bem de todos. Contudo, não ignora a existência de conflitos de interesses, ainda que a sociedade seja um empreendimento cooperativo que visa o beneficio mútuo.

Rawls (2008, p. 12) sustenta que a justiça deve ser entendida como o equilíbrio apropriado entre as existências conflitantes. Define a concepção de justiça, inerente a todos os indivíduos participantes do processo de cooperação, como um conjunto de princípios correlacionados que objetiva identificar as considerações relevantes que determinam esse equilíbrio.

Fixados os conceitos de justiça e concepção de justiça, concebe a estrutura básica da sociedade através de princípios que proporcionem o estabelecimento da divisão de vantagens 
sobre as parcelas distributivas apropriadas, e afirma (2008, p. 5) que os princípios da justiça social são "um modo de atribuir direitos e deveres nas instituições básicas da sociedade e definem a distribuição apropriada dos benefícios e dos encargos da cooperação social”.

O funcionamento desse esquema dependeria da existência de uma sociedade regida por uma concepção pública de justiça, a qual define como aquela em que

(1) todos aceitam e sabem que os outros aceitam os mesmos princípios de justiça; (2) as instituições sociais fundamentais geralmente atendem, e em geral se sabe que atendem, a esses princípios (RAWLS, 2008, p. $5)$.

Define, então (2008, p. 6), a concepção pública de justiça como "aquilo que constitui a carta fundamental de uma associação humana bem ordenada", aí incidindo as especificações dos direitos e deveres fundamentais, bem como a definição das parcelas distributivas apropriadas.

Nessa teoria, a sociedade é vista como um sistema equitativo de cooperação. Assim, a distribuição dos encargos e benefícios deve ser respaldada por princípios discutidos e aceitos pelo corpo social. Ciente de que a pluralidade de valores influenciaria na tomada dessas decisões, bem como de que os princípios deveriam ser construídos acima de interesses de grupos ou classes, Rawls (2008, p. 21 e 166) sugere uma criação hipotética denominada posição original, na qual ocorre a reunião para debate e deliberação desses princípios.

A posição original é balizada por um fator de imparcialidade, essencial para se alcançar a justiça como equidade, justificando-se que os indivíduos presentes não carreguem para a deliberação valores de ordem pessoal, como também conhecimento sobre suas origens, posições sociais, gostos e predileções morais. Essa neutralização ocorre porque os indivíduos estão cobertos pelo véu de ignorância, que os impede de reconhecerem em si e nos demais tais circunstâncias (RAWLS, 2008, p. 166), ou, como sustenta Gargarella (2008, p. 21),

os impede de conhecer qual é a sua classe ou status social, a sorte ou desventura que tiveram na distribuição de capacidades naturais, sua inteligência, sua força, sua raça, a geração a qual pertencem etc.

Rawls (2008, p. 167) ainda adverte que esses indivíduos presentes na posição original são dotados de racionalidade, porque podem compreender o que é bom para si, como também de razoabilidade, que propicia a capacidade de conceber um ideal de justiça e de assim se comportarem no trato social com o grupo.

É justamente a dotação de racionalidade dos indivíduos da posição original que permite a otimização das escolhas feitas, ou, como identificado por Rawls, a estipulação de uma regra denominada maximin, assim esclarecida por Gargarella (2008, p. 23-24): 
A mencionada regra afirma que, nesses momentos de incerteza, devem ser hierarquizadas as diferentes alternativas de acordo com seus piores resultados possíveis. Neste sentido, deverá ser adotada a alternativa cujo pior resultado for superior ao pior dos resultados das outras afirmativas. A escolha dessa regra não surge de um viés 'conservador' dos participantes, mas da peculiar situação em que estão inseridos: os sujeitos em questão não sabem qual é a probabilidade que têm a seu alcance; nem têm um particular interesse em benefícios maiores que o mínimo; nem querem opções que envolvam riscos muito graves. Um exemplo claro do que se quer evitar é o seguinte. Se uma das alternativas em questão permite que alguns terminem em uma situação de virtual escravidão, essa situação será inaceitável, por mais que possa outorgar grandes benefícios à maioria restante.

Esses princípios são escolhidos por pessoas livres e racionais que visam a promoção de seus próprios interesses, aceitando-os como princípios norteadores em uma situação inicial de igualdade para a definição das condições fundamentais de sua associação.

Aqui nasce a justiça como equidade: a discussão em situação inicial (posição original) de igualdade (véu da ignorância), para captação dos princípios norteadores da estrutura básica da sociedade (escolha de direitos e deveres fundamentais/divisão dos benefícios sociais), leiase, norteadores de uma concepção de justiça, a partir da cooperação mútua entre seres livres e racionais que chegarão às regras de equilíbrio.

Rawls (2008, p. 21) afirma que a posição original é o status quo apropriado para garantir que os acordos fundamentais nele alcançados sejam equitativos, na medida em que pressupõe que pessoas racionais escolheriam determinados princípios de justiça.

Para explicar o êxito na identificação da posição original, Rawls (2008, p. 22) sustenta que o alcance equitativo deve pressupor que

ninguém seja favorecido ou desfavorecido pelo acaso ou pelas circunstâncias sociais na escolha dos princípios. Também parece haver consenso geral de que deve ser impossível adaptar os princípios às circunstâncias de casos pessoais. Também devemos garantir que determinadas inclinações e aspirações e concepções individuais do bem não tenham influência sobre os princípios adotados.

Cientes de que a demanda poderia refletir distribuições injustas, os participantes optam por reservar preliminarmente uma categoria de bens em situação de equiparação social, visando a proteção de qualquer invasão ou privação do que seria indispensável para concretização de um projeto de vida boa. Dessa feita, essa lista de bens primários outorga uma categoria de direitos básicos que assumem prioridade sobre o sistema de distribuição, alcançando-se o primeiro princípio: "cada pessoa deve ter um direito igual ao sistema total mais extenso de iguais liberdades fundamentais que seja compatível com um sistema similar de liberdade para as outras pessoas" (RAWLS, 2008, p. 73).

É importante ressaltar que a visão de Rawls acerca do que se compreende como liberdades básicas, em princípio não se deve confundir com a visão ampliativa proporcionada 
no constitucionalismo brasileiro. Esse núcleo básico seria inicialmente limitado aos direitos civis e políticos ${ }^{3}$. Assim, foram elencados: a liberdade política (o direito ao voto e a exercer cargo público) e a liberdade de expressão e reunião; a liberdade de consciência e de pensamento; a liberdade individual, aqui incidindo a proteção contra a opressão psicológica, a agressão e a mutilação (integridade da pessoa); o direito à propriedade pessoal e a proteção contra a prisão e detenção arbitrárias, segundo o conceito do Estado de Direito (RAWLS, 2008, p. 74).

Sandel (2012, p. 189) esclarece o raciocínio para deliberação do primeiro princípio: "não sacrificaríamos nossos direitos e nossas liberdades fundamentais em prol de benefícios sociais ou econômicos", o que respalda uma refutação eloquente da concepção utilitária.

A partir do momento em que os indivíduos se respaldam contra uma eventual tentativa de supressão do núcleo de direitos fundamentais, pois os princípios são enumerados em ordem léxica, são realizadas as deliberações sobre igualdade e diferença.

Decide-se, então, o segundo princípio ${ }^{4}$ :

as desigualdades sociais e econômicas devem estar dispostas de tal modo que tanto (a) propiciem o máximo benefício esperado para os menos favorecidos como (b) estejam vinculadas a cargos e posições abertos a todos em condições de igualdade equitativa de oportunidades (RAWLS, 2008, p. 100).

O princípio em questão revela não apenas a refutação de um sistema aleatório de igualdade, na medida em que tal circunstância resultaria na equiparação dos resultados decorrentes de esforços e talentos empregados de forma diferenciada, bem como que o desempenho de determinadas posições poderia gerar uma renda maior. Tais diferenças serão aceitas se, e somente se, houver garantia de uma equidade das oportunidades.

O princípio da diferença, a propósito, pode ser entendido como forma de desigualdade controlada (BRITO FILHO, 2012, p. 143), e que pode ser assim entendido:

1) ninguém pode ter tudo, mesmo que isso seja amealhado licitamente, pelo que, ao menos pela tributação, uma parte deverá reverter à sociedade; 2) ninguém pode ficar sem alguma coisa, cabendo aos indivíduos um mínimo que deve ser garantido.

A contextualização do pensamento de Rawls ainda reflete a necessidade de se compreender a aplicação dos dois princípios de justiça não apenas como um mínimo padrão para todos (de liberdade e igualdade), mas um mínimo adaptado às necessidades individuais.

\footnotetext{
${ }^{3}$ Rawls salienta ser bastante difícil ou quase impossível fazer uma especificação completa dessas liberdades independentemente das circunstâncias sociais, econômicas e tecnológicas de cada sociedade, o que já reproduz uma ideia não hermética, apesar de sua visão liberal. (RAWLS, 2008, p. 75)

${ }^{4}$ Importante ressaltar que a construção do $2^{\circ}$ princípio sofre modificação no capítulo $\mathrm{V}$ da obra, quando Rawls aborda as parcelas distributivas na sociedade.
} 
Enquanto construção liberal, a justiça como equidade não seria tolerante com uma modulação das liberdades dispostas no $1^{\circ}$ princípio. Assegurar um lote igual ao maior sistema possível a todos significa que, ainda que numa feição mínima, esses direitos civis e políticos não poderiam ser subjugados, exceto quando em conflito direto com outros da mesma natureza. Podem ser citados como exemplos a legítima defesa, a interceptação telefônica judicialmente autorizada, o desforço imediato do direito civil e a suspensão dos direitos políticos.

Em Rawls, essa modulação, ou um padrão (standard) mínimo, ocorreria, sem maiores problemas, pela interpretação sistemática do princípio da diferença.

Que argumentos, então, poderiam ser apresentados para garantia desse padrão (standard) mínimo, que salvaguardaria qualidade de bem estar ao indivíduo, propiciando a atuação das estruturas básicas em direção à tutela do que pode ser considerado um mínimo adaptado às necessidades individuais?

Devemos interpretar a aplicação do princípio da diferença, na justiça como equidade, como uma taxação ou mera compensação aqueles que possuem condições privilegiadas na disputa pela concretização dos planos de vida? Ou, contrariamente, é possível atribuir ao princípio da diferença a condição de mola mestra que conduz a justiça como equidade à tutela eficaz de uma justiça distributiva, apta a proteger o indivíduo da existência em condições aquém do mínimo socialmente aceitável? Se a resposta for positiva à última indagação, qual seria esse mínimo?

Para responder a essas questões, antes, é necessário compreender como John Rawls interpreta o chamado mérito moral e, também, como os dois princípios de justiça são aplicados em ordem léxica à estrutura das instituições públicas.

Apresentaremos primeiramente, com o intuito de encerrar essa parte de exposição das teorias, o libertarismo preconizado por Robert Nozick, com o intuito de estabelecer comparativo entre as teorias, o que demonstra qual o alcance, dentro do liberalismo, da introdução do princípio da diferença, e como isso, naturalmente, conduz à conclusão apresentada neste texto.

\section{LIBERTARISMO}

Uma das formas de negar os preceitos de que o Estado é responsável pelo bem estar material do indivíduo é através do libertarismo, proposição que enaltece o livre mercado. Robert Nozick, na obra "Anarquia, Estado e Utopia", de 1974, produziu uma linha de pensamento filosófico na qual questiona a ideia de justiça distributiva e por via de consequência qualquer 
tipo de compensação não voluntária, expondo os princípios libertários a um eixo no qual a solidariedade não se coaduna.

Esse preceito libertário se apresenta de forma diretamente contrária às ponderações ralwsianas, tendo como diretriz o livre mercado e plenitude do direito de propriedade, sem qualquer tendência a paternalismos estatais.

A partir de um "Estado Mínimo", repudia qualquer tentativa de invasão às liberdades do indivíduo, conferindo-lhes, assim, um potencial hermeticamente vedado à justiça distributiva. A tributação que tenha a finalidade de redistribuir riqueza e renda é absolutamente inaceitável, porque violenta o direito de propriedade e o esforço do indivíduo que lutou para constituir seu patrimônio (NOZICK, 2011, p. 33).

Segundo Kymlicka (2006, p. 119):

Os libertários defendem as liberdades de mercado e exigem limitações ao uso do Estado para a política social. Portanto, eles se opõem ao uso de esquemas de tributação redistributiva para implementar uma teoria liberal de igualdade. Contudo, nem todos os que preferem o mercado livre são libertários, pois nem todos compartilham a visão libertária de que o mercado livre é inerentemente justo.

Desde que a formação patrimonial ocorra de forma lícita, o indivíduo tem a liberdade de decidir o que efetivamente fazer com ele, não sendo possível ao Estado utilizar o produto do esforço individual para qualquer tipo de compensação social, ainda que em benefício dos mais necessitados, justamente porque todos devem agir livremente para consecução de seus projetos de vida.

O "Estado Mínimo" deve não apenas ser impedido de fomentar a redistribuição de riqueza e tributar a renda, como também não deve assumir conotação de restrição à liberdade humana. Nesse sentido, Sandel (2012, p. 79) elenca as rejeições libertárias de três tipos de diretrizes e leis que o Estado moderno normalmente promulga:

1. Nenhum paternalismo. Os libertários são contra as leis que protegem as pessoas contra si mesmas (...) 2. Nenhuma legislação sobre a moral. Os libertários são contra o uso da força coerciva da lei para promover noções de virtude ou para expressar as convicções morais da maioria (...) 3. Nenhuma redistribuição de renda ou riqueza. A teoria libertária dos direitos exclui qualquer lei que force algumas pessoas a ajudar outras, incluindo impostos para redistribuição de riqueza. Embora seja desejável que o mais abastado ajude o menos afortunado subsidiando suas despesas de saúde, moradia e educação -, esse auxílio deve ser facultativo para cada indivíduo, e não uma obrigação ditada pelo governo. De acordo com o ponto de vista libertário, taxas para redistribuição são uma forma de coerção e até mesmo de roubo.

Não há, dessa forma, qualquer margem para aplicação do princípio da solidariedade, visto que contraria frontalmente a concepção libertária de não intervenção na vida privada, sob 
pena de constituir o indivíduo em objeto ou propriedade do Estado. O núcleo de liberdades do indivíduo impede, assim, uma conotação de responsabilidade social.

A visão libertária de justiça de Nozick (2011, p. 297-299) é totalmente contrária à desenhada por Rawls, na medida em que claramente não é aceita uma concepção prioritária ou preestabelecida, tal qual a ordem léxica dos princípios na justiça como equidade, fincando seus parâmetros de justiça na estrita liberdade de escolha do indivíduo a partir do livre mercado, desde que respeitada a legalidade de sua aquisição e/ou de sua transferência.

Rejeita-se, portanto, qualquer pretensão de compensação. As conquistas dos indivíduos são reconhecidas através de seus méritos, o que nos motiva discutir a visão específica sobre o que Rawls considerava vantagens imerecidas, como será apresentado no item seguinte.

\section{MERITOCRACIA E LOTERIA NATURAL}

Ao abordar a tendência à igualdade, Rawls destaca que as desigualdades de berço e de talentos naturais são imerecidas e exigem algum tipo de compensação. Por que razão? Porque não nos foi dado o direito de opção por nascer em um lar mais ou menos abastado, mais ou menos estruturado ou que nos proporcionasse vantagens ou desvantagens na corrida para concretização dos planos racionais de vida.

Se o indivíduo não tem o condão de escolher esses atributos e, portanto, não exerce contribuição direta para tal dotação, sua utilização desenfreada e sem qualquer tipo de modulação importaria em alterar um equilíbrio necessário na conflituosa busca pelos bens considerados escassos na sociedade, como a educação, por exemplo.

Por tal razão, Rawls (2008, p. 120) assim constrói seu raciocínio sobre o princípio da diferença:

O princípio postula que, para tratar a todos com igualdade, oferecer genuína igualdade de oportunidades, a sociedade deve dar mais atenção aos possuidores de menos dotes inatos e aos oriundos de posições sociais menos favoráveis. A ideia é reparar o viés das contingências na direção da igualdade. Na aplicação desse princípio, talvez se viessem a despender mais recursos com a educação dos menos inteligentes, pelo menos durante certo período da vida, digamos, os primeiros anos da escola.

Essa transformação acaba por propiciar uma visão de que a distribuição dos talentos naturais seja um bem comum, de forma que aqueles já favorecidos pela natureza possam se beneficiar de sua boa sorte, desde que essa utilização implique a melhoria da situação dos que estiverem em situação de desvantagem. 
Segundo Rawls (2008, p. 121),

Os naturalmente favorecidos não devem beneficiar-se apenas por serem mais talentosos, mas somente para cobrir os custos de educação e treinamento dos menos favorecidos e para que usem seus talentos de maneira que também ajudem os menos favorecidos. Ninguém merece sua maior capacidade natural nem um ponto de partida mais favorável na sociedade.

A proposta então apresentada não deve se confundir com um ideal de padronização da igualdade, como se o Estado pudesse migrar para um ambiente de igualdade absoluta entre os indivíduos. A tônica é admitir tais desigualdades, mas ajustar as instituições para que trabalhem no sentido de compensá-las no interesse primário daqueles que mais necessitam.

A arbitrariedade do lugar social seria, então, mitigada pela redistribuição de vantagens, permitindo que os menos afortunados também sejam tratados com a consideração necessária para que encontrem mecanismos eficazes para alcançar seus planos de vida.

Ao rejeitar a manutenção aleatória das vantagens imerecidas, Rawls (2008, p. 122) assevera:

Podemos rejeitar o argumento de que a organização das instituições é sempre deficiente, porque a distribuição dos talentos naturais e as contingências das circunstâncias sociais são injustas, e essa injustiça deve, inevitavelmente, transportar-se às instituições humanas. De tempos em tempos essa ponderação é apresentada como desculpa para ignorar a injustiça, como se recusar-se a aquiescer à injustiça fosse o mesmo que a incapacidade de aceitar a morte. A distribuição natural não é justa nem injusta; nem é injusto que se nasça em determinada posição social. Isso são meros fatos naturais, Justo ou injusto é o modo como as instituições lidam com esses fatos. As sociedades aristocráticas e de castas são injustas porque fazem dessas contingências a base adscritícia para o confinamento em classes sociais mais ou menos fechadas e privilegiadas.

Esse contexto prestigia uma valorização da solidariedade, na qual os menos afortunados podem observar que os arranjos institucionais permitem desigualdades. Porém, não é tolerado que a sorte do acaso possa decidir de forma irremediável a distribuição de parcelas vantajosas na sociedade.

A disposição da diferença implica em reconhecer que a todos será dada a oportunidade de concretizar seus planos de vida, estando a estrutura básica da sociedade orientada para tanto. Ainda que a loteria natural tenha sido mais benevolente com alguns, essa circunstância não será enraizada para inviabilizar que o indivíduo com menor condição possa, numa dimensão de cooperação, exercer sua autonomia em busca do bem traçado em seus planos.

Embora esteja clara a proposta de solidariedade no princípio da diferença, que protege o indivíduo menos favorecido, essa digressão ainda não nos responde se o referido princípio meramente objetiva compensar as chamadas vantagens imerecidas. Para averiguar se é possível defender a estruturação de um arranjo social que permita um padrão mínimo de bem estar, é 
necessário analisar a disposição dos quatro estágios adequados na aplicação dos princípios de justiça.

\section{A SEQUÊNCIA DE QUATRO ESTÁGIOS}

A estruturação da teoria da justiça como equidade, a partir da posição original e do véu da ignorância, permite observar que a escolha dos princípios de justiça deve estar atrelada a um ideal de imparcialidade. Como já frisado em item anterior, a deliberação sobre quais princípios devem regular o funcionamento da estrutura social encontra em indivíduos mutuamente desinteressados e racionais, que nada sabem sobre suas origens, posições e predileções, mas detentores de uma concepção pública de justiça, seu ponto de partida.

Contudo, a sequência de quatro estágios para aplicação dos dois princípios à estrutura social nos remete ao fato de que o véu da ignorância é retirado paulatinamente, na medida em que avançam na sequência desses estágios e não imediatamente após a escolha dos princípios.

Após a adoção dos princípios da justiça na posição original, as partes formam uma convenção constituinte: decidem acerca da justiça das formas políticas e escolhem uma constituição, elaborando um sistema para os poderes constitucionais do governo e para os direitos fundamentais. O véu da ignorância, aqui, é parcialmente retirado, permitindo que as pessoas conheçam fatos genéricos sobre a sociedade.

Ou seja, ao findar esse $1^{\circ}$ estágio na escolha da constituição justa, os indivíduos racionais e livres, mutuamente desinteressados, já conseguem identificar o nível de desenvolvimento econômico da sociedade, embora ainda não saibam seu efetivo lugar nas posições sociais, pois, como frisado, o véu da ignorância foi apenas parcialmente retirado.

No $2^{\circ}$ estágio, a partir da constituição, os indivíduos devem escolher, dentre os arranjos procedimentais, os que tenham condições de gerar as ordenações processuais com maior probabilidade de conduzir a uma ordem legal justa e eficaz.

Para tanto, o véu da ignorância é mais uma vez encolhido, pois será necessário o conhecimento de convicções e também dos interesses aos quais os indivíduos estão inclinados. Porém, notoriamente, desconhecem os indivíduos específicos que eventualmente serão atingidos de uma forma mais ou menos direta por esse acervo legislativo.

Assim, a deliberação requer cuidados, pois nós, enquanto indivíduos representativos, não temos ideia do quanto seremos atingidos pelas escolhas e, certamente, não tendo 
conhecimento se somos extremamente inclinados à apostas, a tendência é buscar equilíbrio e proteção.

Rawls (2008, p. 242) assevera categoricamente que não há qualquer sistema de normas políticas capaz de garantir que uma legislação injusta será promulgada, isso porque o melhor sistema que se pode alcançar é o da justiça procedimental imperfeita.

O $3^{\circ}$ estágio ocorre com a avaliação da justiça das leis e das políticas sociais. O legislador representativo que efetuará essa avaliação continua a não ter conhecimento de particularidades sobre si mesmo. $\mathrm{O}$ arcabouço legislativo deve atender não só aos princípios de justiça, mas a quaisquer limites impostos pela constituição. Observe-se que o $1^{\circ}$ princípio atua como padrão principal da convenção constituinte, enquanto o $2^{\circ}$ entra em ação no estágio da legislatura. Logo, a prioridade do primeiro princípio de justiça em relação ao segundo se expressa na prioridade da convenção constituinte em relação ao estágio legislativo.

A atuação do $2^{\circ}$ princípio no estágio de legislatura implica a maximização das expectativas de longo prazo daqueles que estejam em situação menos favorecida, através de políticas sociais e econômicas. Os esforços devem canalizar o preenchimento de espaços vazios em relação às possibilidades de cumprimento dos planos de vida dos que não foram abastados na loteria natural.

Esse é um ponto extremamente importante para se decidir acerca da leitura da teoria da justiça de John Rawls. A sustentação de que o princípio da diferença apenas e tão somente proporciona uma compensação pelas vantagens imerecidas não é suficiente para explicar, por exemplo, que motivação os indivíduos teriam para celebrar um acordo no qual a ordenação do sistema legislativo não assegurasse um esquema de proteção adequado às necessidades do indivíduo.

Também não explica como esse reducionismo poderia afetar a racionalidade das partes na posição original. Deixaremos para o próximo item uma análise mais pormenorizada desses dois fatores.

O $4^{\circ}$ estágio reside na aplicação das normas a casos específicos por juízes e administradores, e a observância das normas pelos cidadãos em geral. Aqui o véu da ignorância é totalmente retirado e, portanto, todos têm acesso a todas as informações sobre a estrutura social, suas posições e predileções.

\section{A JUSTIÇA COMO EQUIDADE PROPORCIONA PROTEÇÃO OU APENAS COMPENSAÇÃO POR DESIGUALDADES?}


Ao expor a constituição da posição original, Rawls menciona que as deliberações ali existentes são produzidas por indivíduos racionais e mutuamente desinteressados. Dizer que tais indivíduos são mutuamente desinteressados implica reconhecer que possuem planos racionais de vida e, que, portanto, têm interesse em sua própria concepção de bem, exatamente naquilo que atinge seus planos, não nos planos dos demais.

A racionalidade implica uma ponderação baseada em preceitos tais quais os imperativos categóricos. Como assevera Rawls (2008, p. 312), a escolha sobre os princípios de justiça é "objeto de escolha racional. Eles definem a lei moral que os homens podem racionalmente almejar para dirigir sua conduta numa comunidade ética".

Se a autonomia para Kant advém do exercício de uma conduta movida por princípios que independem de sua condição social ou de seus dotes naturais, atrelada, portanto, a imperativos categóricos, o resultado obtido pelo agir segundo um desinteresse mútuo, como proposto por Rawls, teria basicamente o mesmo significado.

Ou seja, se as escolhas prudenciais devem nortear um agir correto, e se tais escolhas refletem a essência da lei moral que rege a sociedade, não é possível admitir que tal racionalidade possibilite estabelecer um arranjo de cooperação social fraterno, no qual os menos afortunados não tenham qualquer garantia de proteção mínima.

Admitir que o princípio da diferença, adotado por indivíduos racionais e mutuamente desinteressados, possa meramente cumprir um papel de tarifação sem qualquer propósito de resguardo mínimo daqueles que estão em uma faixa de desvantagem significa admitir que as pessoas na posição original assumem riscos, o que, pela hipótese do véu da ignorância (não sabemos se gostamos ou não de correr riscos), é descartado.

A tolerância às desigualdades econômicas e sociais do $2^{\circ}$ princípio poderá atribuir um mínimo adaptado às necessidades individuais, desde que, e somente se, respeitada a ordem léxica em relação ao $1^{\circ}$ princípio, houver demonstração inequívoca de que a inobservância desse mínimo proporcione a supressão do exercício de suas liberdades.

A despeito de já ter sido frisado claramente que o procedimento legislativo não assegura que leis injustas possam ser promulgadas, na medida em que atrelado à justiça procedimental imperfeita, a passagem reflexiva do personagem Jean Valjean ${ }^{5}$, demonstra

\footnotetext{
5 Jean Valjean, personagem de "Os miseráveis" (VITOR HUGO, 2002), durante o período de sua prisão, cumprindo pena nas Galés, produz intenso raciocínio reflexivo sobre a proporcionalidade entre o crime que praticou (roubo de um pão, além de fugas da prisão), as circunstâncias sociais que o levaram a praticar o ilícito e a pena aplicada (19 anos, incluindo as fugas), chegando à conclusão de que seu crime não foi maior do que o erro da sociedade, produzindo, assim, um cenário bem esclarecedor e prático do que seria a justiça procedimental imperfeita em Rawls.
} 
justamente o que a racionalidade não poderia permitir - ausência de proteção mínima para os mais necessitados, sobejamente dos que não foram agraciados pela loteria natural.

Num sistema montado para a cooperação social, em que a distribuição das parcelas imerecidas deve ser vista como o melhor para a vantagem social, os indivíduos ali participantes não fariam acordos acerca das regras de funcionamento desse sistema nas quais não houvesse um padrão mínimo de segurança, pois admitir essa supressão implica reconhecer inexoravelmente que em uma sociedade de graves desigualdades sociais e econômicas as liberdades garantidas no $1^{\circ}$ princípio poderão ser parcialmente inócuas.

Se o sistema de cooperação social busca constantemente seu fortalecimento e estabilidade através de uma concepção pública de justiça, os indivíduos efetivamente buscarão proteger suas vidas e seus planos não apenas com as liberdades imprescindíveis para execução desses planos, como também estabelecer, a partir dos quatro estágios de aplicação dos princípios de justiça, um padrão mínimo adaptado às necessidades individuais.

Por derradeiro, que influência o equilíbrio reflexivo poderia propiciar nessa leitura da teoria da justiça? Como proposto (RAWLS, 2008, p. 58), a justiça como equidade adota a tônica no sentido de que os princípios de justiça escolhidos na posição original são idênticos aos compatíveis com nossos juízos ponderados.

O equilíbrio reflexivo é caracterizado como um resultado de juízo ponderado no qual se chega após avaliar diversas concepções propostas, quer reconsiderando em todo ou em parte suas concepções iniciais, quer apegando-se às mesmas.

O resultado que se chega, quando são fixados os dois princípios de justiça, é obtido através de equilíbrio reflexivo. O procedimento legislativo promovido nos quatro estágios de aplicação desses princípios à estrutura básica também atua em equilíbrio reflexivo, porque o debate político de construção do sistema normativo atende aos interesses de toda a sociedade.

O liberalismo que envolve a justiça como equidade não tolera restrições às liberdades, ainda que maiores vantagens sociais e econômicas possam advir dessa operação. Já se frisou que as liberdades estabelecidas no $1^{\circ}$ princípio só podem sofrer mitigação entre si. Esse postulado léxico é inarredável.

Contudo, na deliberação do $2^{\circ}$ princípio, em que o equilíbrio reflexivo atua para obter todos os resultados e consequências possíveis, a escolha maximin, ou seja, a escolha do melhor entre o pior dos arranjos possíveis, não permitiria a escolha de um arranjo que permitisse ao indivíduo viver sem proteção ou retaguarda. 
A sustentação dessa proteção ocorre através da compensação em decorrência de vantagens imerecidas, vantagens essas que propiciam as desigualdades na busca pelos bens e pela satisfação dos planos racionais de vida.

E como operaria essa compensação? Garantindo algum pacote mínimo de recursos além dos já previamente estabelecidos no pacote das liberdades do $1^{\circ}$ princípio? Sim. Um arranjo de sistema de cooperação social montado de forma a redistribuir compensações em razão de vantagens imerecidas deve ser direcionado para atender as necessidades mínimas adaptadas às necessidades individuais, e isso só pode ocorrer se algum bem-estar material estiver garantido.

\section{CONCLUSÃO}

As contribuições da teoria da justiça de John Rawls para a filosofia política são inquestionáveis, não apenas porque ultrapassam com êxito a discussão teleológica do justo, como demonstram procedimentalmente a adequada colocação do justo previamente à concepção de bem.

É importante ressaltar que a intepretação ampliativa do princípio da diferença está em perfeita consonância com os propósitos delineados por Rawls, ao indicar a posição original e o equilíbrio reflexivo como fatores necessários para se alcançar a justiça como equidade.

A leitura padrão de manter o princípio da diferença como mera compensação reduz a matriz de solidariedade da teoria, retirando-lhe força de coerência por não conseguir explicar de forma eloquente o que levaria indivíduos com uma concepção de justiça e a incerteza sobre suas posições sociais e econômicas a acatar um acordo que não garante, efetivamente, o pleno exercício de suas liberdades básicas.

A necessidade de uma releitura acurada da obra tem o propósito de demonstrar que a solidez do acordo também se respalda na eloquência de sua pertinência ética de gerar probabilidades de que a comunidade não permitiria que seus cidadãos menos afortunados pudessem sobreviver à margem do mínimo digno.

Essa leitura, que, como vimos, encontra suporte suficiente na teoria de Rawls, abre espaço para sua utilização como base para um modelo que sustenta, de forma eficaz, a concessão a todos os indivíduos de direitos fundamentais sociais, e que toma como dogma que essa concessão respeite a individualidade das pessoas, pois esse é um aspecto sempre valorizado na teoria da justiça como equidade. 


\section{REFERÊNCIAS}

BRITO FILHO, José Claudio Monteiro de. Direito fundamental à saúde: propondo uma concepção que reconheça o indivíduo como seu destinatário. A Leitura/Caderno da Escola Superior da Magistratura do Estado do Pará, Belém, Pará, v. 5, n. 9, p. 136-145, novembro 2012.

GARGARELlA. Roberto. As teorias da justiça depois de Rawls. 1. ed. Trad. Alonso Reis Freire, rev. Elza Maria Gasparotto. São Paulo: Martins Fontes, 2008.

HUGO, Victor. Os miseráveis. 1. ed. Trad. Frederico Ozanam Pessoa de Barros, rev. Sandra Brasil. São Paulo: Cosac Naify, 2002.

KYMLICKA, Will. Filosofia política contemporânea. 1. ed. Trad. Luís Carlos Borges, rev. Marylene Pinto Michael. São Paulo: Martins Fontes, 2006.

NOZICK, Robert. Anarquia, Estado e Utopia. 1. ed. Trad. Fernando Passos, rev. Jefferson Luiz Camargo. São Paulo: Martins Fontes, 2011.

RACHELS, James. Os elementos da filosofia da moral. 4. ed. Trad. Roberto Cavallari Filho, rev. José Geraldo A. B. Poker. Barueri: Manole, 2006.

RAWLS, John. Uma teoria da justiça. 3. ed. Trad. Jussara Simões, rev. Álvaro De Vita. São Paulo: Martins Fontes, 2008.

SANDEL, Michael. Justiça: o que é fazer a coisa certa. Rio de Janeiro: Civilização Brasileira, 2012.

VITA, Álvaro de. A justiça igualitária e seus críticos. 2. ed. São Paulo: Martins Fontes, 2007.

O liberalismo igualitário: sociedade democrática e justiça internacional. 1. ed. São Paulo: Martins Fontes, 2008.

Justiça liberal: argumentos liberais contra o neoliberalismo. 1. ed. Rio de Janeiro: Paz e Terra, 1993. 